\title{
Depression and multiple sclerosis: Review of a lethal combination
}

\author{
Mitchell T. Wallin, MD, MPH; ${ }^{1-3^{*}}$ Jeffrey A. Wilken, PhD;1,3-4 Aaron P. Turner, PhD; ${ }^{5-6}$ Rhonda M. \\ Williams, PhD; ${ }^{5-6}$ Robert Kane, $\mathbf{P h D}^{3-4}$ \\ ${ }^{1}$ Washington, DC, Department of Veterans Affairs (VA) Medical Center, Washington, DC; ${ }^{2}$ Department of Neurology, \\ Georgetown University, Washington, DC; ${ }^{3}$ Maryland VA Healthcare System, Multiple Sclerosis Center of Excellence \\ (MSCoE) East, Baltimore, MD; ${ }^{4}$ Department of Psychology, University of Maryland, College Park, MD; ${ }^{5}$ VA Puget \\ Sound Health Care System, MSCoE West, Seattle, WA; ${ }^{6}$ Department of Rehabilitation Medicine, University of Wash- \\ ington, Seattle, WA
}

\begin{abstract}
Depression is the most frequent psychiatric disorder in multiple sclerosis (MS) patients. The etiology of depression is multifactorial and likely associated with psychosocial stress, focal demyelinating lesions, and immune dysfunction. Proper diagnosis and severity assessment are critical prior to initiation of therapy. Patients with suicidal ideation should be referred for immediate psychiatric consultation and be closely monitored. While more therapeutic trials for depression in MS are needed, MS patients have been shown to respond to current antidepressant medications and psychotherapy. Unfortunately, patients with MS and major depression or suicidal thoughts are often underassessed and therefore not diagnosed. Unlike other aspects of MS, depression is treatable. Early intervention in depression can prevent declines in quality of life and even death from suicide. This article reviews the unique features, assessment, and treatment of depression in MS. MS care providers should vigilantly assess depression and suicide risk in their patients.
\end{abstract}

Key words: assessment, depression, morbidity, mortality, multiple sclerosis, outcome, prevention, review, suicide, treatment.

\section{INTRODUCTION}

Multiple sclerosis (MS) is the most common progressive neurological disease of young adults and currently affects 350,000 persons in the United States [1-2]. Typically, the course of MS starts with random exacerbations and then slowly becomes progressive. Affective disturbances in MS were first noted by Charcot. In 1874 he observed that the intellectual and emotional faculties of patients with MS were "blunted in their totality" [3]. Depression, in particular, is frequently seen in patients with MS but has only recently received attention in the literature. This article highlights the unique features, assessment, and treatment of depression in MS.

\footnotetext{
Abbreviations: AHCPR = Agency for Health Care Policy and Research; BDI = Beck Depression Inventory; BDI-FS = BDI-Fast Screen; $\mathrm{CBT}$ = cognitive-behavioral therapy; DSM = Diagnostic and Statistical Manual of Mental Disorders; DSM-IV = DSM, Fourth Edition; ECT = electroconvulsive therapy; FAMS = Functional Assessment of Multiple Sclerosis; IFN = interferon; IL = interleukin; MRI = magnetic resonance imaging; $\mathrm{MS}$ = multiple sclerosis; POMS = Profile of Mood States; QOL = quality of life; SEG = supportive-expressive group (therapy); SIT = stress inoculation training; SSRI = selective serotonin reuptake inhibitor; STAR $* \mathrm{D}=$ sequenced treatment alternatives to relieve depression; TMAP $=$ Texas Medication Algorithm Project; TNF = tumor necrosis factor; VA = Department of Veterans Affairs.

*Address all correspondence to Mitchell T. Wallin, MD, MPH; Neurology Service 127, VA Medical Center, 50 Irving Street NW, Washington, DC 20422; 202-745-8148; fax: 202-745-8231. Email: mitchell.wallin@med.va.gov

DOI: 10.1682/JRRD.2004.09.0117
} 
Depression is the most frequent psychiatric diagnosis in patients with MS [4]. The lifetime risk for depression in patients with MS ranges from 40 to 60 percent [5]. Interestingly, age and sex-adjusted prevalence rates were twice as high in patients with MS compared with patients with other chronic diseases in a Canadian populationbased study [6]. Patients with MS also have more severe depressive symptoms compared with patients with other chronic neurological diseases [7-9]. One study found that only about one-third of patients with MS and major depression or suicidal thoughts received treatment by their healthcare providers [10]. Both healthcare providers and patients need further education about the identification of at-risk patients and the initiation of therapy.

A number of reasons may explain the association of MS with depression [11], including-

1. The psychosocial effects of MS disability.

2. The direct effect of lesions on brain structures that are involved in regulating and maintaining mood state.

3. The untoward effects of interferon (IFN)- $\beta$ for treating MS, which may be associated with mood changes.

4. Immune dysfunction.

\section{PSYCHOSOCIAL EFFECTS OF MULTIPLE SCLEROSIS}

Depression in MS may be a consequence of the multiple challenges associated with managing a chronic illness. In addition to neurological deficits, MS is frequently associated with losses in vocational status, social roles, sense of control, and participation abilities [12]. The nature of MS is unpredictable and potentially unrelenting. Perceptions regarding the uncertainty in disease, intrusiveness in daily activities, and lack of hope have been associated with depression [13]. Life stress and coping abilities may also mediate psychosocial outcomes [14].

\section{Physical and Cognitive Impairment}

Global physical impairment has been associated with higher levels of depression in some studies [15-17] but not others [11,18]. At first glance, the relationship between impairment and depression appears to be mixed. However, a clearer relationship between depression and impairment appears when studies use more focused measures of physical impairment. For example, Minden et al. found no link between depression and disease severity at a global level; however, depressive episodes were likely to occur within 1 month of a steroid-treated exacerbation of MS [18]. Similarly, another study found increased prevalence of depression during times of MS exacerbations and increased physical impairment [13].

In addition to temporal variation, certain types of physical disability may be differentially related to depression. For example, a recent study of veterans found that perceived mobility and bladder impairment were not associated with increased risk of depression but reports of perceived bowel impairment and "at least occasional" falls were associated with elevated risk of depression [19]. A possible explanation for these findings comes from Devins et al. who found that the relationship between physical disability and depression is indirect: disability affects psychosocial outcome to the degree that impairment is intrusive and personal control is threatened [20].

Physical and cognitive impairments are differentially related to functional outcomes, which highlights the need for separate consideration of these areas [21]. Persons with high levels of cognitive impairment are less likely to work outside the home, more likely to require assistance with activities of daily living, and more likely to have limited social support [22-23]. Some studies have indicated that patients with MS-related cognitive impairment report higher levels of depression than patients without cognitive impairment [24-25]. Other studies do not support this relationship [26-27]. Some evidence exists that the specific type of cognitive impairment may be differentially related to depression. For example, Kenealy et al. found that MS patients with impaired autobiographical memory were less likely to be depressed than those with intact autobiographical memory [28]. The link between cognitive impairment and depression is further complicated by possible bidirectional influence. Not only may cognitive impairment precipitate depression, but depression in a patient with MS may also result in reduced attention and working memory capacity [29]. In sum, depression and cognition are clearly related independent of physical disability, but more research is required for a better understanding of this link.

\section{Vocational Changes}

In the general population, increased risk of depression is associated with unemployment, disability, "homemaker" status, and living at or near the poverty level [30]. A recent population-based study found that persons with disabilities were 5.0 times more likely than persons without disabilities to lose their jobs [31]. The rates of depression were higher among persons with disabilities than persons without disabilities; unemployment status explained nearly 30 percent 
of the elevated depression found in the group with disabilities. The authors argue that the effects of unemployment and disability on depression are independent and additive.

In the MS literature, the links between unemployment and depression are mixed. Given that a majority of patients with MS lose their jobs and about one-third experience a decrease in standard of living [32-33], vocational and financial losses may mediate the relationship between MS and depression. Unemployment among patients with MS is associated with a lower quality of life (QOL) [34]. Williams et al. reported that unemployment was the strongest predictor of a major depressive episode in persons with MS and that the odds of depression were 3.2 times higher among those who were unemployed [19]. This contrasts with a large community-based sample of patients with MS in which unemployment was not associated with depression [17]. Further research will clarify the relationship between vocation and depression in patients with MS.

\section{Social Changes}

Studies have generally found that lower levels of perceived social support are associated with depression in MS [16,25]. A significant portion of patients with MS report qualitative changes in social networks and personal relationships as a result of their disease [16,25,35], including the loss of professional colleagues, diminished contact with social groups, and loss of social independence [36]. Concurrently, many patients with MS become increasingly reliant on care providers and core family members, which often increases caregiver burden [34]. Marital status appears to remain relatively constant after MS diagnosis [32], and many married patients with MS report that they obtain most support from their spouse [37]. However, patients with the highest levels of MS disability perceive less overall support, and those with longer duration of illness perceive less affective and affirmation support than those with shorter duration of illness [37]. A number of studies have found that woman and unmarried persons with MS are at particular risk for diminished social support during their illness [36,38]. Moreover, unsupportive relationships are significantly and independently correlated with depression and a lower sense of purpose [39]. Future studies of social support should address the influence of both supportive and unsupportive behaviors.

\section{Coping}

Most research on coping in MS has relied heavily on Lazarus and Folkman's model that describes coping as "constantly changing cognitive and behavioral efforts to manage specific external and/or internal demands that are appraised as taxing or exceeding the resources of the person" [40]. This model (and subsequent modifications) suggests that most coping strategies available to an individual experiencing a stressor fall into two global yet distinct categories: emotion-focused coping and problemfocused coping. Emotion-focused coping most often represents the individual's reactive efforts to reduce distress caused by the stressor (e.g., avoidance, wishful thinking). Problem-focused coping represents the individual's active efforts to change a stressful situation through modifications of the environment, his- or herself, or the actual stressor (e.g., information gathering, goal setting).

Several studies have identified a link between emotionfocused coping and poor adjustment in MS; depression was the most common outcome reported. In cross-sectional surveys, emotion-focused coping has been related to lower self-esteem [41], global distress [42-44], and depression $[13,15,45-46]$. Similar results were found in studies that examined the relationship between coping styles and depression over time [47-48]. One common interpretation of these findings is that emotion-focused coping is ineffective and leads to poorer adjustment. However, others have argued that in a progressive degenerative disease with often limited opportunities for actively reducing disability or symptoms, emotion-focused coping may be useful and be a substantial portion of a patient's available coping efforts. Furthermore, seemingly passive strategies such as acceptance may have important benefits [12,49].

The relationship between problem-focused coping and adjustment in MS is less well established. Problemfocused coping has been linked to higher self-esteem [41], global distress [42], and depression [15,45], but other studies have failed to find a correlation [13,43-44]. Longitudinal studies have sometimes found associations between problem-focused coping and depression. This link, however, is often observed only at one of several time points and not when emotion-focused coping is examined simultaneously [47-48]. Despite limited data, problem-focused coping is viewed as particularly promising because it has been associated with well-being in general population samples [40] and because problem-focused strategies are the foundation of many psychosocial interventions. Certain problem-focused coping strategies are also argued to be more helpful than others or only appropriate in particular circumstances [12]. These important nuances may be lost in studies that measure coping with global scales. 


\section{BRAIN LESIONS AND MOOD}

Generally, changes in mood have been associated with neurological illnesses with a subcortical component. Since MS affects myelin and the integrity of nerve conduction, mood changes may be a direct neurological consequence of the disease. Several studies have looked at the association between brain lesions and mood changes. Di Legge et al. reported findings from a group of patients with clinically isolated syndromes [50]. They monitored patients for relapse and conversion to MS and found an increased rate of depression in patients who were developing MS. They also reported an association between lesions in the right temporal region and depression severity.

Pujol et al. investigated the relationship between depressive symptoms in MS and lesions in the frontal and temporal lobes [51]. Using a standardized magnetic resonance imaging (MRI) protocol, they studied white matter lesions in tracts connecting these two lobes of the brain. Lesions in the suprainsular white matter (arcuate fasciculus) were significantly associated with depressive symptoms.

Mohr et al. reported a relationship between brain lesion volume and depression in patients with MS and major depression [52]. Patients were enrolled in one of three 16-week treatment programs. They were studied at the end of treatment and 6 months later. At the end of treatment, Beck Depression Inventory (BDI) scores were positively associated with right temporal periventricular lesion volume and left temporal gray-white junction lesion volume. At 6-month follow-up, BDI scores were positively associated with total lesion volume, lesion volume in multiple discrete areas, and neuropsychological functioning.

Bakshi et al. used MRI to study the relationship between lesion location, brain atrophy, and depression in patients with MS [53]. The presence of depression was related to $\mathrm{T} 1$ lesions in the superior frontal and superior parietal regions. Depression severity was related to $\mathrm{T} 1{ }^{*}$ lesions in the superior frontal, superior parietal, and temporal areas. Depression severity was also related to lateral and third ventricle enlargement and frontal atrophy. The authors postulated that depression in MS may be related to atrophy and disconnections between cortical and subcortical regions as a result of frontal and parietal destructive lesions in white matter.

\footnotetext{
*Longitudinal relaxation time that reflects time taken for nuclei to return to thermal equilibrium.
}

This hypothesis is consistent with other studies of brain lesions in depressed patients. Kumar et al. reported a relationship between prefrontal lobe volume and depression severity in patients with late onset major and minor depression [54]. In a review of the literature on MRI findings in psychiatric disorders, Kanner noted that changes in the prefrontal cortex, mesial temporal structures, and the basal ganglia appeared to be related to depression [55]. Videbech and Ravnkilde reported that white matter lesions in the frontal lobes, insula, and areas adjacent to the basal ganglia were associated with major depression [56]. They emphasized the importance of the frontostriatal pathways in depression.

Importantly, not all studies that assess the association between brain lesions and depression have reported positive findings. For example, Millefiorini et al. studied 18 patients in the early phase of relapsing-remitting MS [57]. Using criterion from the Diagnostic and Statistical Manual of Mental Disorders (DSM), Third Edition-Revised, they classified six patients with major depression, seven with minor depression, and five with no depression. No significant differences were found between these three groups in neurocognitive impairment or cerebral lesions as assessed by MRI. However, the authors reported a significant relationship between depression scores and MS disability as measured by the Expanded Disability Status Scale. One limitation of this study was the small number of subjects, which possibly reduced their power to detect differences based on lesion load.

In a larger study, Clark et al. studied multiple measures of ventricular size in 123 MS patients with mild disability and 60 matched controls [58]. They found significant correlations between ventricular enlargement and neurocognitive dysfunction in the MS group. However, no relationship was found between ventricular size and depression as measured by the BDI.

Generally, studies that support a relationship between brain lesions and depression appear to focus on damage to particular areas or the interruption of particular pathways within the brain. Hence, the location of the lesions appears to be an important factor.

\section{INTERFERON- $\beta$ THERAPY AND DEPRESSION}

Initial suspicion of a link between IFN- $\beta$ and depression in MS arose after reports of a suicide and attempted suicides during the first trial of IFN- $\beta$ - $1 \mathrm{~b}$ [59]. Thyroid disease, including hyperthyroidism and hypothyroidism, 
has also been linked to treatment with IFN- $\beta$ [60]. Thyroid disease may masquerade as depression, and this possibility should be evaluated as part of the clinical assessment. Hence, for some patients, an association may exist between the use of IFN- $\beta$ and symptoms of depression.

While the possibility of a link between depression and IFN- $\beta$ exists and must be considered by the clinician, recent studies have not shown a clear association. Borras et al. reported findings from the first 2 years of a longitudinal study of MS patients treated with IFN- $\beta-1 \mathrm{~b}$. At the onset of treatment, 90 patients were assessed, then 75 after 1 year and 56 after 2 years [61]. Worsening depression was not indicated in this study but rather a slight improvement in symptoms of depression and anxiety. Patten and Metz assessed depression in 365 patients with secondary progressive MS treated with either IFN- $\beta$ - 1 a (Rebif ${ }^{\circledR}$ ) or placebo [62]. No significant differences were noted between the two groups during 36 months of follow-up. Zephir et al. assessed depression in 106 MS patients treated with IFN- $\beta$-1a (Avonex ${ }^{\circledR}$ ) [63]. At baseline, 85 percent of their patients had minimum or mild depression. Most of the patients (83\%) retained their baseline status at the 12-month follow-up. Increased depression appeared to be correlated with increased disability. In contrast, the Controlled High-Risk Subjects Avonex ${ }^{\circledR}$ MS Prevention Study group, which evaluated IFN- $\beta-1$ a therapy during a first demyelinating event, reported significantly more depression in the treatment group than the placebo group [64]. Hence, evidence to date from controlled studies does not establish a strong link between treatment with IFN- $\beta$ and depression.

How to treat depression that occurs during IFN- $\beta$ therapy is not settled. Once depression has been diagnosed, discontinuation of IFN- $\beta$ is not the preferred option. Current evidence suggests that pharmacotherapy or psychotherapy for treatment of depression in MS, irrespective of its association to IFN- $\beta$, is a prudent strategy [65].

\section{IMMUNE DYSFUCTION AND DEPRESSION}

Depression has been associated with an activated immune system. Compared with controls, depressed patients have increased numbers of activated $\mathrm{T}$ cells and acute phase proteins and higher production of proinflammatory cytokines, such as tumor necrosis factor (TNF)- $\alpha$, interleukin (IL)-6, IL-1 $\beta$, and IFN- $\gamma$ [66-70]. Lanquillon et al. found significantly decreased TNF- $\alpha$ levels in depressed patients who clinically responded to amitriptyline therapy compared with nonresponders [71]. This cytokine may be, therefore, a marker of psychopathological improvement.

MS is a chronic inflammatory demyelinating disease with predominantly $\mathrm{T}$ cell-mediated immune dysfunction. Like patients with depression, patients with MS have higher serum concentrations of proinflammatory cytokines [72]. Mohr et al. studied 14 patients with relapsing-remitting MS and major depressive disorder over 14 weeks [73]. They found that higher production of the proinflammatory cytokine IFN $-\gamma$ by autoaggressive T cells in patients with MS was related to depression severity. Moreover, treatment of depression with both psychotherapy or pharmacotherapy may decrease IFN- $\gamma$ production. Mohr et al. argue that the treatment of depression in patients with MS may not only provide mood stabilization but also a novel diseasemodifying strategy.

Models that relate stress, cytokines, the endocrine system, and depression are supported in the literature [74-75]. In their literature review, O'Brien et al. noted that cytokines modulate corticotropin-releasing hormone, which produces heightened hypothalamic-pituitary-adrenal axis activity and increased adrenocorticotropic hormone and cortisol [74]. Whether these hormonal changes are primary or secondary pathological defects in the origin depression has yet to be determined. More research is needed for evaluation of the unique immune-endocrine relationships and their effect on mood in patients with MS.

\section{ASSESSMENT OF DEPRESSION}

Because depression is common and can temporarily fluctuate in patients with MS, healthcare providers must have the necessary tools to make timely and accurate diagnoses [62]. One difficulty in diagnosing depression in MS is that many depressive symptoms are observed in MS patients without mood disorders. For example, both fatigue and cognitive dysfunction associated with MS are common and must be considered by the provider in the differential diagnosis of depression. Although more rare, patients with MS can exhibit pathological laughter or crying that poorly correlates with the underlying mood. This syndrome of emotional lability typically occurs with bilateral forebrain disease [76]. Given the overlap of symptoms between depression and MS, the diagnosis of depression in patients with MS is often complicated. Therefore, researchers and clinicians have used psychometrically validated measures of mood to aid their differential diagnosis. 
Historically, there have been two main theoretical frameworks for using validated instruments in the assessment of depression in people with MS. In the first framework, the main goal of assessment is to directly address the symptoms of depression. This is helpful when healthcare providers need to conduct rapid triage and diagnosis so that fast, directed treatment decisions can be made. The second framework looks at depressive symptoms in the context of other MS-related symptoms and emotional responses (e.g., fatigue, low self-esteem, anxiety) that affect overall QOL.

For the busy clinician, the U.S. Preventive Services Task Force recommends a brief two-question screening test for assessing depression (Figure 1) [77-78]. If the answer to one or both questions is positive, the patient should be assessed for the other seven DSM, Fourth Edition (DSM-IV) criteria for major depression. When using this two-question screening test, clinicians should recognize that some patients with MS demonstrate subsyndromal symptoms of depression or mood instability [79] that do not meet the criteria for major depression. These symp-

\section{Two initial screening questions:}

1. Over the past 2 weeks, have you felt down, depressed, or hopeless?

2. Over the past 2 weeks, have you felt little interest or pleasure in doing things?

\section{If one or both questions are positive}

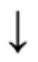

Evaluate major depression based on the following DSM-IV criteria:

Five (or more) of the following nine symptoms have been present during the same 2-week period and represent a change from previous functioning; at least one symptom is either depressed mood or loss of interest or pleasure:

1. Depressed mood.

2. Loss of interest or pleasure.

3. Significant weight loss (when not dieting) or weight gain or decrease in appetite.

4. Insomnia or hypersomnia.

5. Psychomotor agitation or retardation.

6 . Fatigue or loss of energy.

7. Feeling of worthlessness or inappropriate and/or excessive guilt.

8. Diminished ability to think or concentrate, or indecisiveness. 9. Recurrent thoughts of death or suicide.

\section{Figure 1.}

Rapid screening for depression in multiple sclerosis (MS). DSM-IV = Diagnostic and Statistical Manual of Mental Disorders, Fourth Edition. toms are nonetheless associated with significant distress and can respond to therapy. Thus, their detection with the two-question screening test would alert the clinician to the need for treatment. One should note that, despite its face validity, the two-question screening test is not yet validated for use with patients with MS. Thus, at present, it is preferable for clinicians to use an objective depression measure (discussed in the next paragraphs). Objective, validated self-report measures have been used in research on patients with MS, which provides at least some degree of validation. However, the two-question screening test may be useful for busy clinicians who have no time to administer objective measures and would otherwise forego more in-depth depression screening.

The BDI is one of the most commonly used objective self-report depression measures [50]. This inventory has a long history of proven validity for assessing depression in the general public. Though some researchers believe that use of BDI with patients with MS is valid [80], others believe that such use is inappropriate. One main argument against its use is the long administration time. For this reason, several studies have sought to develop questionnaires that assess depressive symptoms in a less time-intensive manner. An example is the Yale Single Question; however, it lacks sensitivity and failed to identify 35 percent of depressed MS patients who had been positively identified on the BDI [81]. Another argument against the use of the BDI with patients with MS is that, because of the high number of items that assess neurovegetative symptoms, it overdiagnoses depression in this population [15]. For that reason, a number of researchers have attempted to identify the BDI items that contain confounds between somatic MS symptoms and neurovegetative symptoms of depression. These studies have resulted in short-forms of the BDI [82]. The best validated BDI short form is the BDIFast Screen (BDI-FS). In a recent study, Benedict et al. validated the BDI-FS with patients with MS [83]. Data from the study supported the concurrent and discriminative validity of the BDI-FS, which indicates that the test did not confound MS-related neurological symptoms. The Chicago Multiscale Depression Inventory is an alternative short instrument that was developed for assessing depression in patients with MS [84]. It was found to have good internal consistency, sensitivity, and construct validity [4].

Based on the idea that a multifactorial approach is the most useful for obtaining a holistic picture of adaptation to MS, one movement in the MS field has been the development of a single multidimensional mood instrument. One such instrument is the Profile of Mood States (POMS), 
which measures mood and multiple dimensions of adaptation, including daily activities, fatigue, and disease status [85]. Unfortunately, although the scale composite score has been found useful, the subscales appear to be intercorrelated [86]. Therefore, the effects of mood relative to other factors cannot be teased apart. A more recently developed multidimensional scale is the Functional Assessment of MS (FAMS). The reliability and validity of the FAMS in patients with MS have been confirmed [87]. The FAMS is divided into six subscales: emotional well-being (depression), mobility, symptoms, general contentment, thinking/ fatigue, and family/social well-being. In their comparison of multiple QOL measures, Nicholl et al. found that the FAMS was the most sensitive measure of the functional domains often associated with decreased QOL in MS patients [88]. In a study that assessed QOL among patients with MS in Spain, MS disability was related to emotional well-being (depression), mobility, and physical symptoms [89]. This study confirms that although depression is certainly a factor in adjustment to MS-related disability, other issues must also be considered and assessed. At this point, little data exist on the FAMS with respect to more global use in the MS community.

Although the best multidimensional tool for assessing depression in patients with MS is currently unclear, the tool must effectively and independently measure both fatigue and depression. Data indicate that depressive symptoms can independently predict fatigue severity [90], and improvement in depressive symptoms appears to be closely associated with decreased fatigue severity [91]. This interaction between depression and fatigue has significant implications for QOL. Research on QOL indicates that the effects of depression on the overall well-being of patients with MS cannot be fully understood without consideration of the presence and severity of fatigue [92]. Given that both depression and fatigue may independently affect [93] and predict [94] QOL, how depression affects the well-being of patients with MS cannot possibly be understood without an evaluation of fatigue. One should note that, in addition to measurement of fatigue, a thorough multidimensional assessment of QOL in depressed MS patients should include, at minimum, a screen of cognitive assessment. In the last few years, the complex interactions among depression, fatigue, and cognition have been repeatedly described in the literature [95-97]. In fact, depressed MS patients clearly perform worse than nondepressed MS patients on measures of cognition [98]. This has significant implications for depressed MS patients with respect to their ability to function in their daily lives. When attempting to refine and expand multidimensional QOL measures, researchers must understand that depression does not exist in a vacuum for patients with MS. Specifically, for such instruments to effectively portray the effects of depression on an MS patient's well-being, they must include items or scales that assess fatigue and cognitive function. Furthermore, multidimensional QOL scales should include some method for interpreting the interaction among depression, fatigue, and cognition. Only then can clinicians and researchers obtain a comprehensive picture of the QOL of depressed MS patients.

In sum, depression is a major problem facing patients with MS and has significant implications for QOL. For this reason, clinicians must perform a depression assessment. Figure 2 offers a model of depression assessment in a typical initial or follow-up clinical visit. For clinicians who do not have enough time to complete objective depression measures, the rapid two-question screening test (Figure 1) gives at least rudimentary information about depressive symptoms and the possibility of a DSM-IV diagnosis. Given that this screen has not been validated, however, a formal objective measure of depression that has been used in research on patients with MS is preferable. The most promising of these formal instruments is the BDI-FS; the Chicago Multiscale Depression Inventory also appears to be a useful unidimensional depression measure for patients with MS. Clinicians who complete a more comprehensive, multidimensional evaluation of depression will find that the results are more helpful in understanding their patients' QOL. Following assessment, the clinician should determine whether further assessment (e.g., neuropsychological assessment) and/or treatment is required.

Multidimensional measures such as the POMS or FAMS offer useful information about mood and assess other domains that might interact with mood and affect patient well-being. Finally, recent research indicates that accurate assessment of the effect of depression on a patient with MS requires a scale that assesses fatigue and cognitive function. If this is not possible in the clinician's office, referral to a neuropsychologist who specializes in MS may be warranted. A neuropsychological evaluation provides a thorough cognitive and psychiatric evaluation and an in-depth assessment of the interaction of depression, cognition, and fatigue.

\section{SUICIDE AND MULTIPLE SCLEROSIS}

Left untreated, MS and depression are unlikely to resolve and may potentially exacerbate each other. The 


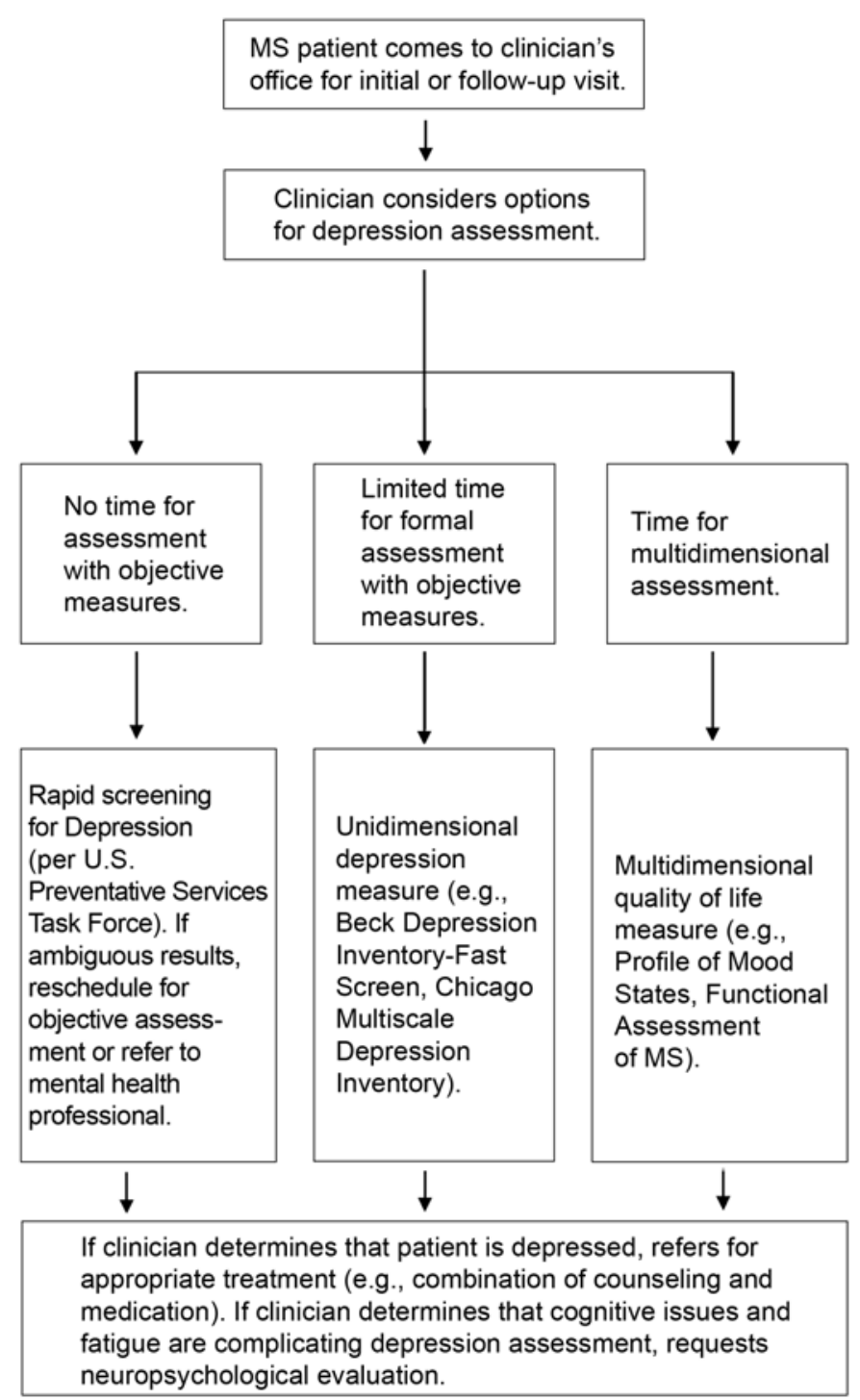

Figure 2.

Assessment of depression in multiple sclerosis (MS).

combination may ultimately lead to suicide. Investigators in Denmark showed that the cumulative lifetime risk for suicide from onset of MS was nearly twice that expected (standardized mortality ratio $=1.85$ ) [99]. Suicide was the cause of 15 percent of deaths in a long-term followup study in Canada between 1972 and 1988 [100].

Feinstein evaluated risk factors for suicide in MS among patients of an outpatient clinic [10]. Severity of major depression, history of alcohol abuse, and living alone had an 85 percent predictive accuracy for suicidal intent. While all patients with MS should be assessed for depression and suicide risk, patients with these additional risk factors should be monitored closely. Male sex, onset of MS before the age of 30, and hopelessness are recognized as important predictors of suicide risk [101-102]. Individuals with suicidal ideation or self-injurious behavior require immediate psychiatric referral and possible inpatient admission.

\section{PSYCHOTHERAPY FOR DEPRESSION}

Psychotherapy has long been recognized as an important treatment for depression in MS. The earliest reports in the literature typically described group-based interventions that improved psychosocial functioning, such as depression, anxiety, understanding of physical limitations, and reduced use of medical services [103104]. Information on inclusion criteria, treatment content, therapist adherence, treatment exposure, and outcome measures was often limited or absent.

\section{Group Cognitive-Behavioral Therapy}

The last three decades have seen a substantial increase in the quantity and rigor of empirical studies examining treatment of depression in MS. Variations on cognitive-behavioral therapy (CBT) are most frequently reported in the literature. Larcombe and Wilson presented the first results of a group-based CBT trial in patients with MS [105]. Patients were randomly assigned to six weekly sessions of traditional CBT or to a wait-list control group. CBT treatment focused on behavioral activation for increasing pleasant activity and social interaction, and on cognitive restructuring for identifying and challenging maladaptive thoughts and beliefs associated with depression. Large, statistically significant reductions in depression were noted across most outcome measures in the treatment group, while small increases in depression were observed in the control group.

In another study of group-based CBT, Crawford and McIvor examined the efficacy of a 13-session stress management program in patients with MS [106]. Individuals who received the intervention $(n=23)$ reported significantly lower levels of depression and anxiety at followup, whereas the control group $(n=21)$ reported increased symptoms.

Somewhat similar results were obtained by Tesar et al. who evaluated a seven-session psychotherapy group that emphasized relaxation training, development of cognitive and behavioral stress coping skills, and exercises 
promoting body awareness [107]. Individuals were quasirandomly distributed so that the first 14 consecutive patients visiting an MS outpatient clinic were assigned to the intervention group and the next 15 were assigned to the control group. Although depression in the intervention group was not significantly decreased relative to the control group, the use of depressive coping strategies was significantly improved.

\section{Individual Cognitive-Behavioral Therapy}

Using a psychological-symptom management program known as stress inoculation training (SIT), Foley et al. compared individuals randomly assigned to six sessions of individual SIT with a wait-list control group that received standard care that included at least some supportive counseling services [108]. Significant reductions in depression and anxiety and increases in problemfocused coping were reported in the SIT group but no corresponding changes were reported for the control group.

In recent years, psychotherapy researchers have increasingly emphasized the tailoring of interventions to the specific needs of patients with MS. Recognizing that physical impairments and fluctuating symptoms may affect a patient's ability to attend clinic appointments and participate in therapy, Mohr et al. developed and evaluated a telephonebased CBT for depression. Individuals were randomly assigned to receive weekly, individual telephone sessions for 8 weeks or to receive usual care [109]. Outcome analyses demonstrated significantly reduced depression in the treatment group but no change in the control group.

\section{Other Psychotherapies}

A small number of studies have addressed the efficacy of other psychotherapy modalities. Crawford and McIvor evaluated an insight-oriented group psychotherapy for treating depression in MS patients [110]. Subjects were randomly assigned to either an insight-oriented treatment group that met twice a week for 25 weeks, a current-events group that met with the same frequency, or a no-treatment control group. Small but significant reductions in depression were noted in the treatment group as compared with the other two groups. Maguire described a six-session group therapy that involved a combination of relaxation training, visualization, and drawing [111]. Participants reported decreases in negative mood states from pre- to posttest, although comparisons between treatment and control groups were problematic.
In the most comprehensive, randomized, controlled trial of treatment for depression in MS, Mohr et al. examined the comparative efficacy of CBT, supportive-expressive group (SEG) therapy, and the antidepressant sertraline [112]. Individuals randomized to the CBT condition received 16 weeks of individual sessions that focused on developing general cognitive and behavioral coping skills and MS-specific management skills. Individuals randomized to the SEG group received 16 weeks of group-based psychotherapy. Significant reductions in depression were noted across all three treatment groups; however, CBT and sertraline more effectively reduced depression scores than SEG. The authors noted that this result opposes findings in nonmedical populations in which all treatments for depression are generally considered equal. This discrepancy supports the hypothesis that depression in patients with MS and possibly other autoimmune diseases is etiologically different from depression in the general population [113-115].

In summary, psychotherapy appears to effectively treat depression in MS. Both group- and individual-based treatments reduce depressive symptoms. CBT interventions that focus on specific coping skills and MS symptom management are generally more effective than interventions that emphasize emotional expression or knowledge. Moreover, CBT is as effective as antidepressant medication.

\section{MEDICATIONS}

Antidepressant medications effectively treat patients with depression and MS [116]. Schiffer and Wineman presented results of the first double-blind placebo-controlled treatment trial of major depressive disorder in patients with MS [117]. A total of 28 patients were enrolled; one half received a 5-week trial of desipramine and psychotherapy and the other half received a placebo and psychotherapy. As evaluated by the Hamilton Rating Scale for Depression and the BDI, patients treated with desipramine improved significantly more than patients in the placebo group. Anticholinergic side effects, however, were reported in a significant majority of desipramine-treated patients. In an open-labeled trial of 11 depressed patients with MS, Scott et al. demonstrated that sertraline was both effective and well tolerated [118]. Similarly, Mohr et al. demonstrated that a 16-week trial of sertraline significantly reduced depression scores in patients with MS and major depressive disorder [112]. 
A number of medical therapeutic options are open to MS patients with depression. Drug classes of major antidepressants and representative medications are listed in the Table. Tricyclic antidepressants are among the oldest and have a long track record of success in treating depression. Their anticholinergic and cardiac side effects are problematic for many patients as noted in the trial by Schiffer and Wineman [117]. In MS patients with significant neurogenic bladder symptoms, however, these anticholinergic effects may be helpful. Newer agents are well tolerated with some subtle differences in side effect profiles. In general, the effectiveness of antidepressants is comparable between and within classes of medications [119]. A particular agent should be chosen based largely on its side effect profile, safety, quality of clinical trial data, cost, and patient preference. The selective serotonin reuptake inhibitors (SSRIs) have been proven to be well tolerated, safe, and effective in patients with MS and are a good initial choice for pharmacotherapy.

A healthcare provider must conduct an adequate trial and assessment period to judge the success of an antidepressant. A stable dose of an individual drug should be given for at least 6 to 12 weeks. Before a medication is started, side effects must be reviewed with the patient and monitored regularly. Finally, response to treatment should be assessed with an easy-to-administer scale, such as the BDI or BDI-FS. A positive response to a particular antidepressant is typically defined as a 50 percent reduction in a standardized depression scale score. A nonresponse to medication is defined as no net change from baseline of the standardized depression scale score [120].

\section{OTHER THERAPIES}

In the general population, up to 70 percent of patients with major depression respond to an adequate antidepressant medication trial. For those who do not respond, alternative approaches are needed. Studies in the general population have shown that regular exercise effectively reduces depression [121]. In a controlled randomized trial, Petajan et al. showed that patients with MS had significantly reduced depression after 15 weeks of aerobic training [122]. For severe depression in MS, electroconvulsive therapy (ECT) has been shown to be useful [123-124]. Some concern remains, however, that ECT may mediate neurological deterioration by altering the number or size of central nervous system plaques [125]. Recent studies in non-MS populations have found that stimulants such as methylphenidate [126] and modafinil [127-128] are useful adjunctive treatments for depression. In general, when therapeutic medication failures are encountered, the dose, compliance, and duration of treatment should be reassessed. Alternatively, the healthcare provider should question the diagnosis and rule out potential depression masqueraders.

Table.

Medication options for depression.

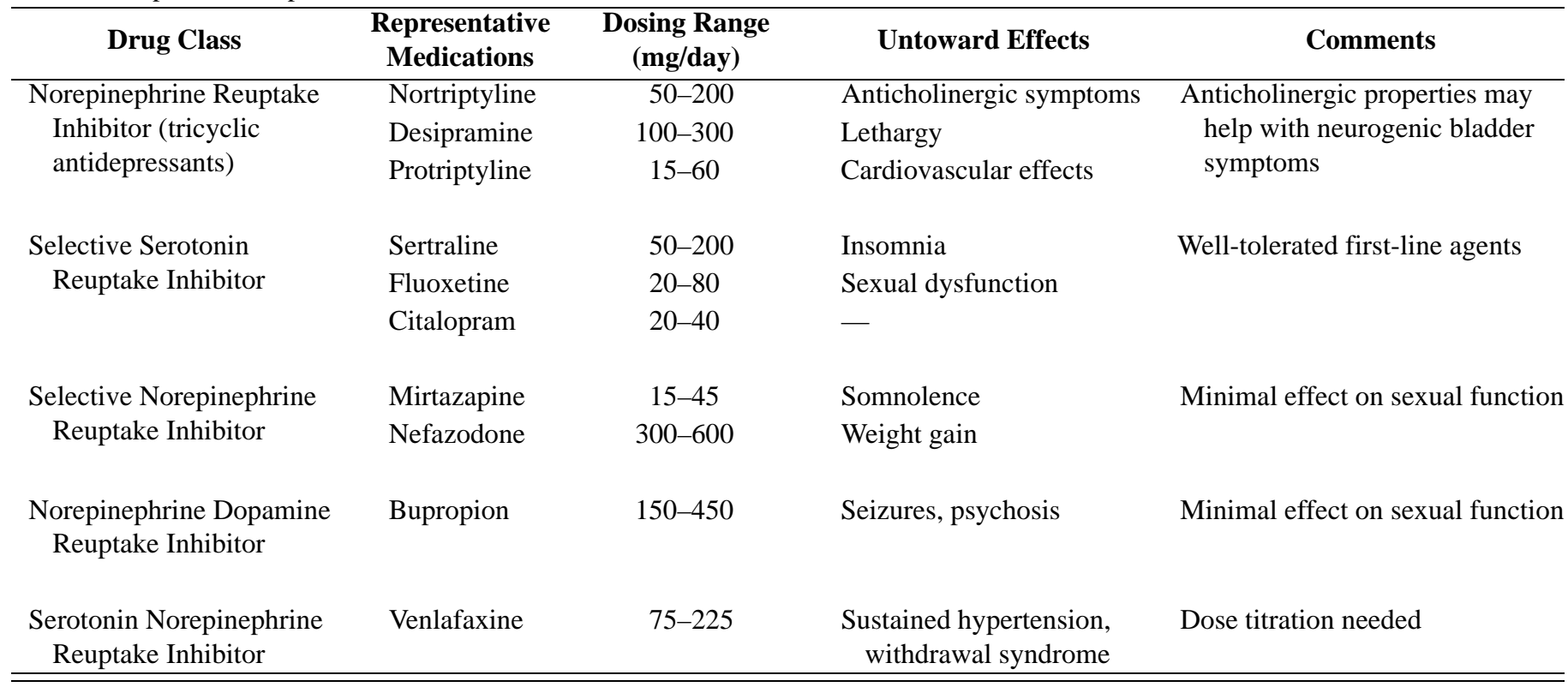




\section{USE OF DEPRESSION GUIDELINES}

Depression in patients with MS is commonly underdiagnosed. The reasons for this underdiagnosis likely parallel those found in general primary care settings where depression is also frequently underdiagnosed. A number of studies have shown that providers' use of guidelines along with a thorough follow-up program in primary care settings can facilitate successful identification and treatment of patients with depression [129-130]. Two frequently cited guidelines for depression treatment were published in 1993 by the Agency for Health Care Policy and Research (AHCPR) [131] and the American Psychiatric Association [132]. A more recent update to the AHCPR guidelines focuses more on their use within primary care settings [133]. The authors found that antidepressant pharmacotherapy and psychotherapies are effective when transferred from the psychiatric to primary care environment. After discussing the options with the patient, the clinician should choose a therapeutic approach based on patient preference. Most importantly, studies have suggested that improved treatment of depression within primary care requires an organized treatment program, regular patient follow-up with monitoring of treatment compliance and, in more severe cases, a prominent role for the mental health specialist.

Despite studies that support guideline implementation, other reports have shown that guidelines fail to improve depression treatment [134-135]. Current evidence suggests that without a structured follow-up system, guidelines are unlikely to be implemented successfully. In many clinics, time and lack of resources often preclude the use of guidelines.

We would argue that the high frequency of depression in patients with MS makes periodic screening as outlined in Figure 1 a high-yield activity. Patients with MS should be screened at least annually for depression. Patients who meet the criteria for depression should be treated with a single antidepressant or psychotherapy based on the previously discussed results. Monitoring with the BDI, BDI-FS, or a similar assessment tool should be performed 4 to 6 weeks after initiation and periodically thereafter. Indications for referral to a mental health specialist should include severe symptoms, suicide risk, comorbid psychiatric or substance abuse disorder, and failure to respond to appropriate treatment.

Treatment algorithms have been developed that address alternative treatments and help the clinician make evidence-based choices. The Texas Medication
Algorithm Project (TMAP) published a depression treatment algorithm that was recently implemented at a number of sites [136]. The TMAP has three major phases: acute (stage 1), continuation (stages 2-4), and maintenance treatment (stage 5). Patients move between stages based on inadequate symptom improvement or untoward effects from therapy. Another algorithm, called sequenced treatment alternatives to relieve depression (STAR*D), is under development [137]. STAR*D is based on a prospective study that randomly assigned patients who had not achieved remission with an SSRI to one of six treatment options. STAR*D and TMAP results regarding compliance, remission, and cost-effectiveness will be very useful for patients with depression and their healthcare providers. More research on the unique treatment issues of MS patients with depression and on the development of effective algorithms is needed.

\section{CONCLUSIONS}

Depression is the most frequent psychiatric disorder in MS patients. Its etiology is multifactorial and associated with focal demyelinating lesions and psychosocial stress. Proper diagnosis and severity assessment are critical prior to initiation of therapy. The method used for measuring depression in the MS population differs depending on the goals of the assessment. Patients with suicidal ideation should be referred for immediate psychiatric consultation and be closely monitored. While more therapeutic trials for depression in MS are needed, patients with MS have been shown to respond to current antidepressant medications. Unfortunately, many patients with MS and major depression or suicidal thoughts are under-recognized and undertreated. Unlike other aspects of MS, depression is treatable and is a potentially preventable cause of death. MS care providers need to vigilantly assess depression and suicide risk in their patients.

\section{ACKNOWLEDGMENTS}

This material was based on work supported by the Department of Veterans Affairs (VA) MS Center of Excellence and a VA Rehabilitation Research and Development Service Career Development Award, grant B3319VA (Dr. Turner). 


\section{REFERENCES}

1. Noseworthy JH, Lucchinetti C, Rodriguez M, Weinshenker BG. Multiple sclerosis. N Engl J Med. 2000;343(13): 938-52. [PMID: 11006371]

2. Anderson DW, Ellenberg JH, Leventhal CM, Reingold SC, Rodriguez M, Silberberg DH. Revised estimate of the prevalence of multiple sclerosis in the United States. Ann Neurol. 1992;31(3):333-36. [PMID: 1637140]

3. Charcot JM. Lectures on diseases of the nervous system. London (England): New Sydenham Society; 1877.

4. Solari A, Motta A, Mendozzi L, Aridon P, Bergamaschi R, Ghezzi A, Mancardi GL, Milanese C, Montanari E, Pucci E. Italian version of the Chicago multiscale depression inventory: translation, adaptation and testing in people with multiple sclerosis. Neurol Sci. 2004;24(6):375-83. [PMID: 14767682]

5. Sadovnick AD, Remick RA, Allen J, Swartz E, Yee IM, Eisen K, Farquhar R, Hashimoto SA, Hooge J, Kastrukoff LF, Morrison W, Nelson J, Oger J, Paty DW. Depression and multiple sclerosis. Neurology. 1996;46(3):628-32. [PMID: 8618657]

6. Patten SB, Beck CA, Williams JV, Barbui C, Metz LM. Major depression in multiple sclerosis: a populationbased perspective. Neurology. 2003;61(11):1524-27. [PMID: 14663036]

7. Dalos NP, Rabins PV, Brooks BR, O’Donnell P. Disease activity and emotional state in multiple sclerosis. Ann Neurol. 1983;13(5):573-77. [PMID: 6870209]

8. Whitlock FA, Siskind MM. Depression as a major symptom of multiple sclerosis. J Neurol Neurosurg Psychiatry. 1980;43(10):861-65. [PMID: 7441263]

9. Schubert DS, Foliart RH. Increased depression in multiple sclerosis patients. A meta-analysis. Psychosomatics. 1993; 34(2):124-30. [PMID: 8456154

10. Feinstein A. An examination of suicidal intent in patients with multiple sclerosis. Neurology. 2002;59(5):674-78. [PMID: 12221156]

11. Joffe RT, Lippert GP, Gray TA, Sawa G, Horvath Z. Mood disorder and multiple sclerosis. Arch Neurol. 1987;44(4): 376-78. [PMID: 3827692]

12. Mohr DC, Cox D. Multiple sclerosis: empirical literature for the clinical health psychologist. J Clin Psychol. 2001; 57(4):479-99. [PMID: 11255203]

13. Lynch SG, Kroencke DC, Denney DR. The relationship between disability and depression in multiple sclerosis: the role of uncertainty, coping, and hope. Mult Scler. 2001; 7(6):411-16. [PMID: 11795464]

14. Schwartz CE, Foley FW, Rao SM, Bernardin LJ, Lee H, Genderson MW. Stress and course of disease in multiple sclerosis. Behav Med. 1999;25(3):110-16.

[PMID: 10640224]
15. Mohr DC, Goodkin DE, Gatto N, Van der Wende J. Depression, coping and level of neurological impairment in multiple sclerosis. Mult Scler. 1997;3(4):254-58. [PMID: 9372510]

16. McIvor GP, Riklan M, Reznikoff M. Depression in multiple sclerosis as a function of length and severity of illness, age, remissions, and perceived social support. J Clin Psychol. 1984;40(4):1028-33. [PMID: 6480837]

17. Chwastiak L, Ehde DM, Gibbons LE, Sullivan M, Bowen JD, Kraft GH. Depressive symptoms and severity of illness in multiple sclerosis: epidemiologic study of a large community sample. Am J Psychiatry. 2002;159(11):1862-68. [PMID: 12411220]

18. Minden SL, Orav J, Reich P. Depression in multiple sclerosis. Gen Hosp Psychiatry. 1987;9(6):426-34. [PMID: 3692149]

19. Williams RM, Turner AP, Hatzakis M Jr, Bowen JD, Rodriquez AA, Haselkorn JK. Prevalence and correlates of depression among veterans with multiple sclerosis. Neurology. 2005;64(1):75-80. [PMID: 15642907]

20. Devins GM, Seland TP, Klein G, Edworthy SM, Saary MJ. Stability and determinants of psychosocial well-being in multiple sclerosis. Rehabil Psychol. 1993;38(1):11-26.

21. Amato MP, Ponziani G, Siracusa G, Sorbi S. Cognitive dysfunction in early-onset multiple sclerosis: a reappraisal after 10 years. Arch Neurol. 2001;58(10):1602-6. [PMID: 11594918]

22. Rao SM, Leo GJ, Ellington L, Nauertz T, Bernardin LJ, Unverzagt F. Cognitive dysfunction in multiple sclerosis. II. Impact on employment and social functioning. Neurology. 1991;41(5):692-96. [PMID: 1823781]

23. Roessler RT, Fitzgerald SM, Rumrill PD, Koch LC. Determinants of employment status among people with multiple sclerosis. Rehabil Couns Bull. 2001;45(1):31-39.

24. Maor Y, Olmer L, Mozes B. The relation between objective and subjective impairment in cognitive function among multiple sclerosis patients-The role of depression. Mult Scler. 2001;7(2):131-35. [PMID: 11424633]

25. Gilchrist AC, Creed FH. Depression, cognitive impairment and social stress in multiple sclerosis. J Psychosom Res. 1994;38(3):193-201. [PMID: 8027959]

26. Krupp LP, Sliwinski M, Masur DM, Friedberg F, Coyle PK. Cognitive functioning and depression in patients with chronic fatigue syndrome and multiple sclerosis. Arch Neurol. 1994;51(7):705-10. [PMID: 8018045]

27. Schiffer RB, Caine ED. The interaction between depressive affective disorder and neuropsychological test performance in multiple sclerosis patients. J Neuropsychiatry Clin Neurosci. 1991;3(1):28-32. [PMID: 7580169]

28. Kenealy PM, Beaumont GJ, Lintern T, Murrell R. Autobiographical memory, depression and quality of life in multiple sclerosis. J Clin Exp Neuropsychol. 2000;22(1): 125-31. [PMID: 10649551] 
29. Arnett PA, Higginson CI, Voss WD, Wright B, Bender WI, Wurst JM, Tippin JM. Depressed mood in multiple sclerosis: relationship to capacity-demanding memory and attentional functioning. Neuropsychology. 1999;13(3):434-46.

[PMID: 10447304$]$

30. Kessler RC, Berglund P, Demler O, Jin R, Koretz D, Merikangas KR, Rush AJ, Walters EE, Wang PS. The epidemiology of major depressive disorder: results from the National Comorbidity Survey Replication (NCS-R). JAMA. 2003;289(23):3095-3105. [PMID: 12813115]

31. Turner JB, Turner RJ. Physical disability, unemployment, and mental health. Rehabil Psychol. 2004;49(3):241-49.

32. Hakim EA, Bakheit AM, Bryant TN, Roberts MW, McIntosh-Michaelis SA, Spackman AJ, Martin JP, McLellan DL. The social impact of multiple sclerosis-A study of 305 patients and their relatives. Disabil Rehabil. 2000; 22(6):288-93. [PMID: 10864132]

33. Roessler RT, Rumrill PD, Fitzgerald SM. Predictors of employment status for people with multiple sclerosis. Rehabil Couns Bull. 2004;47(2):96-103.

34. Aronson KJ. Quality of life among persons with multiple sclerosis and their caregivers. Neurology. 1997;48(1):74-80. [PMID: 9008497]

35. Mohr DC, Dick LP, Russo D, Pinn J, Boudewyn AC, Likosky W, Goodkin DE. The psychosocial impact of multiple sclerosis: exploring the patient's perspective. Health Psychol. 1999;18(4):376-82. [PMID: 10431939]

36. Gulick EE. Social support among persons with multiple sclerosis. Res Nurs Health. 1994;17(3):195-206. [PMID: 8184131]

37. O’Brien MT. Multiple sclerosis: the role of social support and disability. Clin Nurs Res. 1993;2(1):67-85. [PMID: 8453390]

38. Williams RM, Turner AP, Hatzakis M Jr, Chu S, Rodriquez AA, Haselkorn JK. Social support among veterans with multiple sclerosis. Rehabil Psychol. 2004;49(2):106-13.

39. Wineman NM. Adaptation to multiple sclerosis: The role of social support, functional disability, and perceived uncertainty. Nurs Res. 1990;39(5):294-99. [PMID: 2144627]

40. Lazarus RS, Folkman S. Stress, appraisal, and coping. New York (NY): Springer Publishing Company; 1984.

41. O’Brien MT. Multiple sclerosis: the relationship among self-esteem, social support, and coping behavior. Appl Nurs Res. 1993;6(2):54-63. [PMID: 8317939]

42. Wineman NM, Durand EJ, Steiner RP. A comparative analysis of coping behaviors in persons with multiple sclerosis or a spinal cord injury. Res Nurs Health. 1994; 17(3):185-94. [PMID: 8184130]

43. Jean VM, Paul RH, Beatty WW. Psychological and neuropsychological predictors of coping patterns by patients with multiple sclerosis. J Clin Psychol. 1999;55(1): 21-26. [PMID: 10100828]
44. Beatty WW, Hames KA, Blanco CR, Williamson SJ, Wilbanks SL, Olson KA. Correlates of coping style in patients with multiple sclerosis. Mult Scler. 1998;4(5):440-43. [PMID: 9839305]

45. Kroencke DC, Denney DR, Lynch SG. Depression during exacerbations in multiple sclerosis: the importance of uncertainty. Mult Scler. 2001;7(4):237-42. [PMID: 11548983]

46. Pakenham KI, Stewart CA, Rogers A. The role of coping in adjustment to multiple sclerosis-related adaptive demands. Psychol Health Med. 1997;2(3):197-203.

47. Pakenham KI. Adjustment to multiple sclerosis: Application of a stress and coping model. Health Psychol. 1999; 18(4):383-92. [PMID: 10431940]

48. Aikens JE, Fischer JS, Namey M, Rudick RA. A replicated prospective investigation of life stress, coping, and depressive symptoms in multiple sclerosis. J Behav Med. 1997;20(5):433-45. [PMID: 9415854]

49. Brooks NA, Matson RR. Social-psychological adjustment to multiple sclerosis: a longitudinal study. Soc Sci Med. 1982;16(24):2129-35. [PMID: 7157043]

50. Di Legge S, Piattella MC, Pozzilli C, Pantano P, Caramia F, Pestalozza IF, Paolillo A, Lenzi GL. Longitudinal evaluation of depression and anxiety in patients with clinically isolated syndrome at high risk of developing early multiple sclerosis. Mult Scler. 2003;9(3):302-6. [PMID: 12814180]

51. Pujol J, Bello J, Deus J, Marti-Vilalta JL, Capdevila A. Lesions in the left arcuate fasciculus region and depressive symptoms in multiple sclerosis. Neurology. 1997;49(4): 1105-10. [PMID: 9339697]

52. Mohr DC, Epstein L, Luks TL, Goodkin DE, Cox D, Goldberg A, Chin C, Nelson S. Brain lesion volume and neuropsychological function predict efficacy of treatment for depression in multiple sclerosis. J Consult Clin Psychol. 2003;71(6):1017-24. [PMID: 14622077]

53. Bakshi R, Czarnecki D, Shaikh ZA, Priore RL, Janardhan V, Kaliszky Z, Kinkel PR. Brain MRI lesions and atrophy are related to depression in multiple sclerosis. Neuroreport. 2000;11(6):1153-58. [PMID: 10817583]

54. Kumar A, Jin Z, Bilker W, Udupa J, Gottlieb G. Lateonset minor and major depression: early evidence for common neuroanatomical substrates detected by using MRI. Proc Natl Acad Sci U S A. 1998;95(13):7654-58. [PMID: 9636205]

55. Kanner AM. Structural MRI changes of the brain in depression. Clin EEG Neurosci. 2004;35(1):46-52. [PMID: 15112463]

56. Videbech P, Ravnkilde B. Hippocampal volume and depression: a meta-analysis of MRI studies. Am J Psychiatry. 2004;161(11):1957-66. [PMID: 15514393]

57. Millefiorini E, Padovani A, Pozzilli C, Loriedo C, Bastianello S, Buttinelli C, Di Piero V, Fieschi C. Depression in the early phase of MS: influence of functional disability, 
cognitive impairment and brain abnormalities. Acta Neurol Scand. 1992;86(4):354-58. [PMID: 1455980]

58. Clark CM, James G, Li D, Oger J, Paty D, Klonoff H. Ventricular size, cognitive function and depression in patients with multiple sclerosis. Can J Neurol Sci. 1992; 19(3):352-56. [PMID: 1393845]

59. Klapper JA. Interferon beta treatment of multiple sclerosis. Neurology. 1994;44(1):188; author reply 188-90.

[PMID: 8290074]

60. Kreisler A, De Seze J, Stojkovic T, Delisse B, Combelles M, Verier A, Hautecoeur P, Vermersch P. Multiple sclerosis, interferon and clinical thyroid dysfunction. Acta Neurol Scand. 2003;107(2):154-57. [PMID: 12580868]

61. Borras C, Rio J, Porcel J, Barrios M, Tintore M, Montalban $\mathrm{X}$. Emotional state of patients with relapsing-remitting MS treated with interferon beta-1b. Neurology. 1999;52(8): 1636-39. [PMID: 10331691]

62. Patten SB, Metz LM, SPECTRIMS Study Group. Interferon-1a and depression in secondary progressive MS: data from the SPECTRIMS Trial. Neurology. 2002;59(5): 744-46. [PMID: 12221168]

63. Zephir H, De Seze J, Stojkovic T, Delisse B, Ferriby D, Cabaret M, Vermersch P. Multiple sclerosis and depression: influence of interferon therapy. Mult Scler. 2003; 9(3):284-88. [PMID: 12814176]

64. Jacobs LD, Beck RW, Simon JH, Kinkel RP, Brownscheidle CM, Murray TJ, Simonian NA, Slasor NA, Sandrock AW. Intramuscular interferon beta-1a therapy initiated during a first demyelinating event in multiple sclerosis. CHAMPS Study Group. N Engl J Med. 2000; 343(13): 898-904. [PMID: 11006365]

65. Feinstein A. Multiple sclerosis, disease modifying treatments and depression: a critical methodological review. Mult Scler. 2000;6(5):343-48. [PMID: 11064445]

66. Sluzewska A, Rybakowski J, Bosmans E, Sobieska M, Berghmans R, Maes M, Wiktorowicz K. Indicators of immune activation in major depression. Psychiatry Res. 1996;64(3):161-67. [PMID: 8944394]

67. 67. Frommberger UH, Bauer J, Haselbauer P, Fraulin A, Riemann D, Berger M. Interleukin-6 (IL-6) plasma levels in depression and schizophrenia: comparison between the acute state and after remission. Eur Arch Psychiatry Clin Neurosci. 1997;247(4):228-33. [PMID: 9332905]

68. 68. Owen BM, Eccleston D, Ferrier IN, Young AH. Raised levels of plasma interleukin-1 in major and postviral depression. Acta Psychiatr Scand. 2001;103(3):226-28. [PMID: 11240580]

69. Penninx BW, Kritchevsky SB, Yaffe K, Newman AB, Simonsick EM, Rubin S, Ferrucci L, Harris T, Pahor M. Inflammatory markers and depressed mood in older persons: results from the Health, Aging and Body Composition study. Biol Psychiatry. 2003;54(5):566-72. [PMID: 12946885$]$
70. Seidel A, Arolt V, Hunstiger M, Rink L, Behnisch A, Kirchner $\mathrm{H}$. Cytokine production and serum proteins in depression. Scand J Immunol. 1995;41(6):534-38. [PMID: 7539545$]$

71. Lanquillon S, Krieg JC, Bening-Abu-Shach U, Vedder H. Cytokine production and treatment response in major depressive disorder. Neuropsychopharmacology. 2000; 22(4):370-79. [PMID: 10700656]

72. Mikova O, Yakimova R, Bosmans E, Kenis G, Maes M. Increased serum tumor necrosis factor alpha concentrations in major depression and multiple sclerosis. Eur Neuropsychopharmacol. 2001;11(3):203-8. [PMID: 11418279]

73. Mohr DC, Goodkin DE, Islar J, Hauser SL, Genain CP. Treatment of depression is associated with suppression of nonspecific and antigen-specific $\mathrm{T}(\mathrm{H}) 1$ responses in multiple sclerosis. Arch Neurol. 2001;58(7):1081-86. [PMID: 11448297]

74. O’Brien SM, Scott LV, Dinan TG. Cytokines: Abnormalities in major depression and implications for pharmacological treatment. Hum Psychopharmacol. 2004;19(6): 397-403. [PMID: 15303243]

75. Dubas-Slemp H, Marmurowska-Michalowska H, SzusterCiesielska A, Kaminska T, Kandefer-Szerszen M. The role of cytokines in depression [Polish]. Psychiatr Pol. 2003;37(5):787-98. [PMID: 14631599]

76. Schiffer RB, Herndon RM, Rudick RA. Treatment of pathologic laughing and weeping with amitriptyline. N Engl J Med. 1985;312(23):1480-82. [PMID: 3887172]

77. U.S. Preventive Services Task Force. Screening for depression: recommendations and rationale. Rockville (MD): Agency for Healthcare Research and Quality; 2002.

78. American Psychiatric Association. Diagnostic and statistical manual of mental disorders. 4th ed. Arlington (VA): American Psychiatric Association; 1994.

79. Feinstein A, Feinstein K. Depression associated with multiple sclerosis. Looking beyond diagnosis to symptom expression. J Affect Disord. 2001;66(2-3):193-98. [PMID: 11578672]

80. Aikens JE, Reinecke MA, Pliskin NH, Fischer JS, Wiebe JS, McCracken LM, Taylor JL. Assessing depressive symptoms in multiple sclerosis: is it necessary to omit items from the original Beck Depression Inventory? J Behav Med. 1999;22(2):127-42. [PMID: 10374139$]$

81. Avasarala JR, Cross AH, Trinkaus K. Comparative assessment of Yale Single Question and Beck Depression Inventory Scale in screening for depression in multiple sclerosis. Mult Scler. 2003;9(3):307-10. [PMID: 12814181]

82. Mohr DC, Goodkin DE, Likosky W, Beutler L, Gatto N, Langan MK. Identification of Beck Depression Inventory items related to multiple sclerosis. J Behav Med. 1997; 20(4):407-14. [PMID: 9298438] 
83. Benedict RH, Fishman I, McClellan MM, Bakshi R, Weinstock-Guttman B. Validity of the Beck Depression Inventory-Fast Screen in multiple sclerosis. Mult Scler. 2003;9(4):393-96. [PMID: 12926845]

84. Nyenhuis DL, Rao SM, Zajecka JM, Luchetta T, Bernardin L, Garron DC. Mood disturbance versus other symptoms of depression in multiple sclerosis. J Int Neuropsychol Soc. 1995;1(3):291-96. [PMID: 9375223]

85. McNair DM. Manual for the Profile of Mood States. San Diego (CA): Educational and Industrial Testing Service; 1981.

86. Mohr DC, Goodkin DE, Bacchetti P, Boudewyn AC, Huang L, Marrietta P, Cheuk W, Dee B. Psychological stress and the subsequent appearance of new brain MRI lesions in MS. Neurology. 2000;55(1):55-61. [PMID: 10891906$]$

87. Cella DF, Dineen K, Arnason B, Reder A, Webster KA, Karabatsos G, Chang C, Lloyd S, Steward J, Stefoski D. Validation of the functional assessment of multiple sclerosis quality of life instrument. Neurology. 1996;47(1): 129-39. [PMID: 8710066]

88. Nicholl CR, Lincoln NB, Francis VM, Stephan TF. Assessment of emotional problems in people with multiple sclerosis. Clin Rehabil. 2001;15(6):657-68. [PMID: 11777096]

89. Modrego PJ, Pina MA, Simon A, Azuara MC. The interrelations between disability and quality of life in patients with multiple sclerosis in the area of Bajo Aragon, Spain: a geographically based survey. Neurorehabil Neural Repair. 2001;15(1):69-73. [PMID: 11527281]

90. Flachenecker P, Kumpfel T, Kallmann B, Gottschalk M, Grauer O, Rieckmann P, Trenkwalder C, Toyka KV. Fatigue in multiple sclerosis: a comparison of different rating scales and correlation to clinical parameters. Mult Scler. 2002;8(6):523-26. [PMID: 12474995]

91. Mohr DC, Hart SL, Goldberg A. Effects of treatment for depression on fatigue in multiple sclerosis. Psychosom Med. 2003;65(4):542-47. [PMID: 12883103]

92. Voss WD, Arnett PA, Higginson CI, Randolph JJ, Campos MD, Dyck DG. Contributing factors to depressed mood in multiple sclerosis. Arch Clin Neuropsychol. 2002;17(2): 103-15. [PMID: 14589740]

93. Janardhan V, Bakshi R. Quality of life in patients with multiple sclerosis: the impact of fatigue and depression. J Neurol Sci. 2002;205(1):51-58. [PMID: 12409184$]$

94. Amato MP, Ponziani G, Rossi F, Liedl CL, Stefanile C, Rossi L. Quality of life in multiple sclerosis: the impact of depression, fatigue and disability. Mult Scler. 2001;7(5): 340-44. [PMID: 11724451]

95. Romani A, Bergamaschi R, Candeloro E, Alfonsi E, Callieco R, Cosi V. Fatigue in multiple sclerosis: multidimensional assessment and response to symptomatic treatment. Mult Scler. 2004;10(4):462-68.

[PMID: 15327047$]$
96. Schwid SR, Tyler CM, Scheid EA, Weinstein A, Goodman AD, McDermott MP. Cognitive fatigue during a test requiring sustained attention: a pilot study. Mult Scler. 2003;9(5):503-8. [PMID: 14582777]

97. Provinciali L, Ceravolo MG, Bartolini M, Logullo F, Danni M. A multidimensional assessment of multiple sclerosis: relationships between disability domains. Acta Neurol Scand. 1999;100(3):156-62. [PMID: 10478578]

98. Arnett PA, Higginson CI, Voss WD, Bender WI, Wurst JM, Tippin JM. Depression in multiple sclerosis: relationship to working memory capacity. Neuropsychology. 1999;13(4):546-56. [PMID: 10527063]

99. Stenager EN, Stenager E. Suicide and patients with neurologic diseases. Methodologic problems. Arch Neurol. 1992;49(12):1296-1303. [PMID: 1449409]

100. Sadovnick AD, Eisen K, Ebers GC, Paty DW. Cause of death in patients attending multiple sclerosis clinics. Neurology. 1991;41(8):1193-96. [PMID: 1866003]

101. Stenager EN, Stenager E, Koch-Henriksen N, BronnumHansen H, Hyllested K, Jensen K, Bille-Brahe U. Suicide and multiple sclerosis: an epidemiological investigation. J Neurol Neurosurg Psychiatry. 1992;55(7):542-45. [PMID: 1640228]

102. Caine ED, Schwid SR. Multiple sclerosis, depression, and the risk of suicide. Neurology. 2002;59(5):662-63. [PMID: 12221154]

103. Bolding H. Psychotherapeutic aspects in the management of patients with multiple sclerosis. Dis Nerv Syst. 1960; 21:24-26. [PMID: 13802284]

104. Day M, Day E, Herrmann R. Group therapy of patients with multiple sclerosis: a preliminary report. AMA Arch Neurol Psychiatry. 1953;69(2):193-96. [PMID: 13007228]

105. Larcombe NA, Wilson PH. An evaluation of cognitivebehavior therapy for depression in patients with multiple sclerosis. Br J Psychiatry. 1984;145:366-71. [PMID: 6487909]

106. Crawford JD, McIvor GP. Stress management for multiple sclerosis patients. Psychol Rep. 1987;61(2):423-29. [PMID: 3324144$]$

107. Tesar N, Baumhackl U, Kopp M, Gunther V. Effects of psychological group therapy in patients with multiple sclerosis. Acta Neurol Scand. 2003;107(6):394-99. [PMID: 12757470]

108. Foley FW, Bedell JR, LaRocca NG, Scheinberg LC, Reznikoff M. Efficacy of stress-inoculation training in coping with multiple sclerosis. J Consult Clin Psychol. 1987;55(6):919-22. [PMID: 3693660]

109. Mohr DC, Likosky W, Bertagnolli A, Goodkin DE, Van der Wende J, Dwyer P, Dick LP. Telephone-administered cognitive-behavioral therapy for the treatment of depressive symptoms in multiple sclerosis. J Consult Clin Psychol. 2000;68(2):356-61. [PMID: 10780138] 
110. Crawford JD, McIvor GP. Group psychotherapy: benefits in multiple sclerosis. Arch Phys Med Rehabil. 1985; 66(12):810-13. [PMID: 4074113]

111. Maguire BL. The effects of imagery on attitudes and moods in multiple sclerosis patients. Altern Ther Health Med. 1996;2(5):75-79. [PMID: 8795941]

112. Mohr DC, Boudewyn AC, Goodkin DE, Bostrom A, Epstein L. Comparative outcomes for individual cognitive-behavior therapy, supportive-expressive group psychotherapy, and sertraline for the treatment of depression in multiple sclerosis. J Consult Clin Psychol. 2001;69(6): 942-49. [PMID: 11777121]

113. Mohr DC, Goodkin DE. Treatment of depression in multiple sclerosis: review and meta-analysis. Clin Psychol Sci Pract. 1999;6(1):1-9.

114. Dobkin PL, Da Costa D, Joseph L, Fortin PR, Edworthy S, Barr S, Ensworth S, Esdaile JM, Beaulieu A, Zummer M, Senecal JL, Goulet JR, Choquette D, Rich E, Smith D, Cividino A, Gladman D, St-Pierre Y, Clarke AE. Counterbalancing patient demands with evidence: results from a pan-Canadian randomized clinical trial of brief supportive-expressive group psychotherapy for women with systemic lupus erythematosus. Ann Behav Med. 2002;24(2): 88-99. [PMID: 12054324$]$

115. Zautra AJ, Yocum DC, Villanueva I, Smith B, Davis MC, Attrep J, Irwin M. Immune activation and depression in women with rheumatoid arthritis. J Rheumatol. 2004;31(3): 457-63. [PMID: 14994388]

116. Gill D, Hatcher S. Antidepressants for depression in medical illness. Cochrane Database Syst Rev. 2000;(4):CD001312.

117. Schiffer RB, Wineman NM. Antidepressant pharmacotherapy of depression associated with multiple sclerosis. Am J Psychiatry. 1990;147(11):1493-97. [PMID: 2221162]

118. Scott TF, Nussbaum P, McConnell H, Brill P. Measurement of treatment response to sertraline in depressed multiple sclerosis patients using the Carroll scale. Neurol Res. 1995;17(6):421-22. [PMID: 8622794$]$

119. American Psychiatric Association. The practice guidelines for the treatment of patients with major depressive disorder. 2nd ed. Arlington (VA): American Psychiatric Association; 2000.

120. Frank E, Prien RF, Jarrett RB, Keller MB, Kupfer DJ, Lavori PW, Rush AJ, Weissman MM. Conceptualization and rationale for consensus definitions of terms in major depressive disorder. Remission, recovery, relapse, and recurrence. Arch Gen Psychiatry. 1991;48(9):851-55. [PMID: 1929776]

121. Brosse AL, Sheets ES, Lett HS, Blumenthal JA. Exercise and the treatment of clinical depression in adults: recent findings and future directions. Sports Med. 2002;32(12): 741-60. [PMID: 12238939]
122. Petajan JH, Gappmaier E, White AT, Spencer MK, Mino L, Hicks RW. Impact of aerobic training on fitness and quality of life in multiple sclerosis. Ann Neurol. 1996; 39(4):432-41. [PMID: 8619521]

123. Corruble E, Awad H, Chouinard G, Hardy P. ECT in delusional depression with multiple sclerosis. Am J Psychiatry. 2004;161(9):1715. [PMID: 15337668]

124. Coffey CE, Weiner RD, McCall WV, Heinz ER. Electroconvulsive therapy in multiple sclerosis: a magnetic resonance imaging study of the brain. Convuls Ther. 1987; 3(2):137-44. [PMID: 11940906]

125. Mattingly G, Baker K, Zorumski CF, Figiel GS. Multiple sclerosis and ECT: possible value of gadolinium-enhanced magnetic resonance scans for identifying high-risk patients. J Neuropsychiatry Clin Neurosci. 1992;4(2):145-51. [PMID: 1627975]

126. Lavretsky H, Kim MD, Kumar A, Reynolds CF 3rd. Combined treatment with methylphenidate and citalopram for accelerated response in the elderly: an open trial. J Clin Psychiatry. 2003;64(12):1410-14. [PMID: 14728100]

127. DeBattista C, Doghramji K, Menza MA, Rosenthal MH, Fieve RR. Modafinil in Depression Study Group. Adjunct modafinil for the short-term treatment of fatigue and sleepiness in patients with major depressive disorder: a preliminary double-blind, placebo-controlled study. J Clin Psychiatry. 2003;64(9):1057-64. [PMID: 14628981]

128. DeBattista C, Lembke A, Solvason HB, Ghebremichael $\mathrm{R}$, Poirier J. A prospective trial of modafinil as an adjunctive treatment of major depression. J Clin Psychopharmacol. 2004;24(1):87-90. [PMID: 14709953]

129. Jarjoura D, Polen A, Baum E, Kropp D, Hetrick S, Rutecki G. Effectiveness of screening and treatment for depression in ambulatory indigent patients. J Gen Intern Med. 2004;19(1):78-84. [PMID: 14748864]

130. Katon W, Von Korff M, Lin E, Walker E, Simon GE, Bush $\mathrm{T}$, Robinson P, Russo T. Collaborative management to achieve treatment guidelines. Impact on depression in primary care. JAMA. 1995;273(13):1026-31. [PMID: 7897786]

131. U.S. Department of Health and Human Services, Agency for Health Care Policy and Research Clinical Practice Guideline Number 5: Depression in Primary Care, vol 2, Treatment of Major Depression. Rockville (MD): U.S. Department of Health and Human Services, Agency for Health Care Policy and Research; 1993.

132. Practice guideline for major depressive disorder in adults. American Psychiatric Association. Am J Psychiatry. 1993;150(4 Suppl):1-26. [PMID: 8465906$]$

133. Schulberg HC, Katon W, Simon GE, Rush AJ. Treating major depression in primary care practice: an update of the Agency for Health Care Policy and Research Practice 
Guidelines. Arch Gen Psychiatry. 1998;55(12):1121-27. [PMID: 9862556]

134. Goldberg HI, Wagner EH, Fihn SD, Martin DP, Horowitz CR, Christensen DB, Cheadle AD, Diehr P, Simon G. A randomized controlled trial of CQI teams and academic detailing: can they alter compliance with guidelines? Jt Comm J Qual Improv. 1998;24(3):130-42.

[PMID: 10677821]

135. Callahan CM, Hendrie HC, Dittus RS, Brater DC, Hui SL, Tierney WM. Improving treatment of late life depression in primary care: a randomized clinical trial. J Am Geriatr Soc. 1994;42(8):839-46. [PMID: 8046193]

136. Crismon ML, Trivedi M, Pigott TA, Rush AJ, Hirschfeld RM, Kahn DA, DeBattista C, Nelson JC, Nierenberg AA, Sackheim HA, Thase ME. The Texas Medication Algorithm Project: report of the Texas Consensus Conference
Panel on Medication Treatment of Major Depressive Disorder. J Clin Psychiatry. 1999;60(3):142-56.

[PMID: 10192589]

137. Rush AJ, Fava M, Wisniewski SR, Lavori PW, Trivedi MH, Sackeim HA, Thase ME, Nierenberg AA, Quitkin FM, Kashner TM, Kupfer DJ, Rosenbaum JF, Alpert J, Stewart JW, McGrath PJ, Biggs MM, Shores-Wilson K, Lebowitz BD, Ritz L, Niederehe G, STAR*D Investigators Group. Sequenced treatment alternatives to relieve depression (STAR*D): rationale and design. Control Clin Trials. 2004;25(1):119-42. [PMID: 15061154]

Submitted for publication September 3, 2004. Accepted in revised form January 7, 2005. 